\title{
A randomised phase II study of pegylated arginine deiminase (ADI-PEG 20) in Asian advanced hepatocellular carcinoma patients
}

\section{T-S Yang', I', S-N Lu, II, Y Chao ${ }^{3}$, I-S Sheen*,I, C-C Lin', T-E Wang ${ }^{4}$, S-C Chen', J-H Wang', L-Y Liao', JA Thomson ${ }^{7}$, J Wang-Peng ${ }^{8}$, P-J Chen ${ }^{*, 9}$ and L-T Chen ${ }^{*, 5,8,10}$}

'Department of Internal Medicine, Chang Gung Memorial Hospital, LinKou Medical Center, Chang Gung University, Taoyuan 33305, Taiwan; ${ }^{2}$ Department of Internal Medicine, Kaohsiung Chang Gung Memorial Hospital, Kaohsiung 833, Taiwan; ${ }^{3}$ Cancer Center, Taipei Veterans General Hospital, Taipei I 12, Taiwan; ${ }^{4}$ Department of Internal Medicine, Mackay Memorial Hospital, Taipei 10449, Taiwan; ${ }^{5}$ Department of Internal Medicine, Kaohsiung Medical University Hospital, Kaohsiung Medical University, Kaohsiung 807, Taiwan; ${ }^{6}$ Department of Internal Medicine, Ren-Ai Branch, Taipei City Hospital, Taipei 106, Taiwan; ${ }^{7}$ Polaris Pharmaceuticals Inc., San Diego, CA, USA; ${ }^{8}$ National Institute of Cancer Research, National Health Research Institutes, 2F, No. 367, Sheng-Li Road, Tainan 704, Taiwan; ${ }^{9}$ Department of Internal Medicine, National Taiwan University Hospital, Taipei 100 , Taiwan;

${ }^{10}$ Department of Internal Medicine, National Cheng Kung University Hospital and College of Medicine, Tainan 704, Taiwan

BACKGROUND: Human hepatocellular carcinoma (HCC) cells are largely deficient of argininosuccinate synthetase and thus auxotrophic for arginine. This study aims to investigate the efficacy and pharmacodynamics of pegylated arginine deiminase (ADI-PEG 20), a systemic arginine deprivation agent, in Asian HCC patients.

METHODS: Patients with advanced HCC who were not candidates for local therapy were eligible and randomly assigned to receive weekly intramuscular injections of ADI-PEG 20 at doses of 160 or $320 \mathrm{IU} \mathrm{m}^{-2}$. The primary end point was disease-control rate (DCR).

RESULTS: Of the 7I accruals, 43.6\% had failed previous systemic treatment. There were no objective responders. The DCR and the median overall survival (OS) of the intent-to-treat population were 31.0\% (95\% confidence interval (Cl): 20.5 -43.I) and 7.3 (95\% Cl: 4.7-9.9) months respectively. Both efficacy parameters were comparable between the two study arms. The median OS of patients with undetectable circulating arginine for more than or equal to and <4 weeks was 10.0 (95\% Cl: 2.I - I7.9) and 5.8 (95\% Cl: I.4- I0. I) months respectively $(P=0.25 \mathrm{I}$, log-rank test). The major treatment-related adverse events were grades $\mathrm{I}-2$ local and/or allergic reactions.

CONCLUSIONS: ADI-PEG 20 is safe and efficacious in stabilising the progression of heavily pretreated advanced HCC in an Asian population, and deserves further exploration.

British Journal of Cancer (2010) I 03, 954-960. doi:I0.1038/sj.bjc.6605856 www.bjcancer.com

Published online 31 August 2010

(C) 2010 Cancer Research UK

Keywords: arginine; arginine deiminase; hepatocellular carcinoma; polyethylene glycol; argininosuccinate synthetase

Hepatocellular carcinoma (HCC) is one of the most common malignancies in the world (Ryder, 2003; Sun et al, 2003; Yu and Keeffe, 2003; Llovet, 2005; El-Serag and Rudolph, 2007). There are approximately 500000 new cases diagnosed annually worldwide. The majority of them are diagnosed with advanced disease that is not amenable to effective local therapies such as liver transplantation, resection, percutaneous ablation or transcatheter

*Correspondence: Dr L-T Chen; Email: leochen@nhri.org.tw or Professor P-J, Chen; E-mail: peijer@ha.mc.ntu.edu.tw or Professor I-S Sheen; E-mail: issheen.jks@gmail.com

Note: The results of this study were presented at 2009 Gastrointestinal Cancer Symposium, American Society of Clinical Oncology, January 2I-23 2009, San Francisco, California, USA.

11 These authors contributed equally to this work.

Received 9 April 20I0; revised 20 July 20I0; accepted 20 July 2010; published online 31 August 2010 arterial chemoembolisation (TACE) therapy. Systemic chemotherapy, for instance the conventional 'standard' therapy of doxorubicin, has been largely ineffective and typically associated with many side effects (Di Maio et al, 2002; Ryder, 2003; Llovet, 2005; Chen et al, 2006). As a result, placebo has remained as an acceptable control in randomised phase III trials until sorafenib (Nexavar; Bayer HealthCare AG, Leverkusen, Germany) was shown to improve the survival of advanced HCC over placebo in both Caucasian and Asian populations (Llovet et al, 2008; Cheng et al, 2009). Despite odds ratio of 0.6-0.7 compared with placebocontrol in both studies, the absolute improvement was not more than 2-3 months. Therefore, pursuing additional options of effective and tolerable systemic therapies for advanced HCC is still mandatory (O'Neill and Venook, 2007; Abou-Alfa and Venook, 2008; Zhu, 2008).

Arginine is a non-essential amino acid for humans and mice (Rogers, 1994; Tapiero et al, 2002). It is synthesised in humans and 
other mammals from citrulline in two steps through the urea cycle enzymes, argininosuccinate synthetase (ASS) and argininosuccinate lyase (ASL). ASS catalyses the conversion of citrulline and aspartic acid to argininosuccinate, which is then converted to arginine and fumaric acid by ASL. It has long been known that some tumour cells are auxotrophic for arginine, based on the observations that normal cells derived from liver, kidney and testes could grow in medium depleted of arginine but supplemented with citrulline, whereas tumour cells from these organs could not (Tytell and Neuman, 1960). Other investigators reported that certain tumour cell lines could not be maintained in medium contaminated with Mycoplasma species, which could be attributed to arginine depletion mediated by Mycoplasma-produced arginine deiminase (ADI; Kenny and Pollock, 1963; Kraemer et al, 1963; Kraemer, 1964; Sugimura et al, 1990). These observations indicated that ADI, through depletion of circulating arginine, might be a potential anti-cancer agent. The enzyme was cloned and expressed in E. coli and subsequently conjugated to polyethylene glycol (PEG) to increase the circulating half-life and decrease the immunogenicity of the recombinant Mycoplasma enzyme (Takaku et al, 1992, 1993; Holtsberg et al, 2002).

It has been shown that some human HCC and melanoma cell lines and tissue samples do not express ASS, making them auxotrophic for arginine and thus reasonable candidates for arginine deprivation therapy (Ensor et al, 2002; Dillon et al, 2004). The first phase I/II study of pegylated arginine deiminase (ADI-PEG 20) for unresectable HCC was reported in 2004 (Izzo et al, 2004). In that dose-escalating study, $160 \mathrm{IU} \mathrm{m}^{-2}$ was selected as the optimal biologic dose for weekly ADI-PEG 20 therapy, as it sustained depletion of circulating arginine for 7 days. Among the 19 enrolled patients, the best tumour response was objective response in $47.4 \%$ (two CR, seven PR) and stable disease in $36.8 \%$, and the median survival was 410 days. No significant toxicity was observed even in patients who had persistent arginine depletion for 3 or more months. In a more recent phase II study, Glazer et al (2010) showed that this agent could achieve $2.5 \%$ of objective response rate and $65 \%$ of diseases control rate in 80 Caucasian patients with predominantly hepatitis C-related HCC and minimal prior systemic therapy. This parallel phase II study aims to investigate the therapeutic efficacy of ADI-PEG 20 for advanced HCC in an Asian population.

\section{MATERIALS AND METHODS}

\section{Trial design and participants}

This was an open-label, multi-centre, randomised phase II study undertaken in Taiwan. The primary end point of the study was to assess the therapeutic efficacy of ADI-PEG 20 in an Asian HCC population in terms of disease-control rate (DCR), which was defined as radiographic objective response (complete or partial response) or stable disease for 8 or more weeks after ADI-PEG 20 treatment. The secondary end points were overall survival (OS), progression-free survival (PFS) and pharmacodynamics parameters, that is, changes of circulating level of arginine and citrulline and anti-ADI-PEG 20 antibody. The study was approved by the ethics committee at each trial centre and by the Department of Health, Executive Yuan, Taiwan, and all patients signed written informed consent. The study followed the Declaration of Helsinki Principles and Good Clinical Practice guidelines.

\section{Eligibility}

Patients with measurable, metastatic or locally advanced HCC that had failed or were too advanced to have definitive local therapy, that is, surgical resection, percutaneous ethanol or acetic acid injection, TACE, radiofrequency ablation either alone or in combination, were eligible. Patients were considered to have unresectable HCC if their tumours were of either local therapyfailed Barcelona Criteria for Liver Cancer stage B or BLCL stage $C$ (the presence of either major vascular invasion or distant metastases, or in combination). The diagnosis of HCC had to have been established by cytology or histopathology. Patients were also required to be age of $\geqslant 18$ years, and have an expected survival of $\geqslant 12$ weeks, Karnofsky performance score $\geqslant 80$, Child - Pugh score $\leqslant 8$, serum levels of total bilirubin $<2.0 \mathrm{mg}$ per $100 \mathrm{ml}$, albumin $>2.5 \mathrm{~g}$ per $100 \mathrm{ml}$, AST/ALT and alkaline phosphatase $<5 \times$ upper limit of normal (ULN), ammonia $<70 \mu \mathrm{g}$ per $100 \mathrm{ml}$, glucose $>60 \mathrm{mg}$ per $100 \mathrm{ml}$, amylase $<1.5 \times \mathrm{ULN}$, uric acid $\leqslant 8 \mathrm{mg}$ per $100 \mathrm{ml}$ (with or without medication control), peripheral blood absolute neutrophil count $\geqslant 1500$ per $\mu \mathrm{l}$ and platelets $\geqslant 50000$ per $\mu \mathrm{l}$. Female patients of childbearing age and male patients had to use appropriate contraception during the study period. A serum HCG pregnancy test had to be negative before entry. Previous chemotherapy and/or targeted therapy were allowed, but had to be 4 weeks or more (6 weeks for nitrosoureas or mitomycin C) before entering the study, and patients were to be completely recovered from adverse events. Other exclusion criteria included the presence of uncontrolled inter-current illness and a history of other malignancies within 5 years of study entry.

\section{Therapy and clinical assessments}

Enrolled patients would be randomly assigned to receive intramuscular injection of ADI-PEG 20 (Polaris Pharmaceuticals Inc., San Diego, CA, USA) at 160 or $320 \mathrm{IU} \mathrm{m}^{-2}$ on days $1,8,15$ and 22 every 4 weeks (as one cycle). Medical history and physical examination, serum $\alpha$-fetoprotein and uric acid levels, and circulating arginine and citrulline levels were assessed before each ADI-PEG 20 administration. Complete blood count, blood biochemistry tests, coagulation test, urinary analyses and antiADI-PEG 20 antibody titre were assessed after every cycle (4 weeks) of treatment. Circulating arginine and citrulline levels were determined by mass spectrometry assays, and the plasma anti-ADI-PEG 20 antibody level was assessed by the ELISA-based immunogenicity assay. These pharmacodynamic parameter determinations were performed in outsourced central laboratories. Grading of adverse events and assessment of tumour response were performed based on the National Cancer Institute Common Toxicity Criteria, Version 3.0 and the RECIST criteria respectively (Therasse et al, 2002). All the treatments were given until a maximum six cycles (24 weeks) of treatment were reached unless unacceptable toxicity, the refusal of patient, withdrawal of informed consent or death was observed. Those who remained progression free after six cycles of treatment could continue the therapy in an expanded, compassionate use programme.

\section{Statistical considerations}

The primary end point of the study was DCR, which was defined as the ratio of patients with objective tumour response (complete or partial response) or stable disease for $\geqslant 8$ weeks in either dosing arm. Secondary end points were OS, PFS and changes in pharmacodynamic parameters. According to Simon's optimal twostage design for uninterested and interested ORR of 10 and $30 \%$, respectively, with both $\alpha$ and $\beta$ errors probabilities of 0.05 and 0.20 , respectively, 10 patients would be accrued in the first stage of each dosing cohort (Simon, 1989). If $<2$ responders were observed among the initial 10 evaluable patients in either dosing cohort, then the dosing would be considered as ineffective and the accrual in that cohort would be terminated. If $\geqslant 2$ responders were observed among the initial 10 evaluable patients in any dosing cohort, an additional 19 patients would be accrued into the second stage of study. If $\geqslant 6$ responses were observed in any dosing cohort, ADI-PEG 20 would be considered effective; otherwise, it 
would be concluded that ADI-PEG 20 was not effective enough for further exploration in advanced HCC. All patients who received any assigned treatment were included in the intent-to-treat (ITT) population. The definition of an event for OS was death from any cause. The survival distributions were estimated using the Kaplan-Meier method (Kaplan and Meier, 1958). $\chi^{2}$-Test and Fisher's exact test were used for descriptive variables, and Wilcoxon Mann-Whitney approach was used for continuous variables. Any $P$-values $<0.05$ (two-sided test) were considered statistically significant.

\section{RESULTS}

\section{Recruitment and demography of participants}

Between October 2006 and March 2008, 71 patients from eight participating hospitals were enrolled into the study; 37 patients were allocated to the $160 \mathrm{IU} \mathrm{m}^{-2}$ dosing arm and 34 to the $320 \mathrm{IU} \mathrm{m}^{-2}$ dosing arm. There were 59 men $(83.1 \%)$ and 12 women (16.9\%), with a median age of 55 years (range $27-82$ ) and hepatitis B surface antigen seropositive in $49(69.0 \%)$. A total of 63 patients $(88.7 \%)$ had failed previous therapies, including surgery in 29 $(40.8 \%)$, one or more sessions of chemoembolisation in 46 (64.8\%), previous chemotherapy/targeted therapy in $31(43.6 \%)$ and radiation therapy in $19(26.8 \%)$. Demographics of the patients were well balanced except that significantly more patients in the $320 \mathrm{IU} \mathrm{m}^{-2}$ arm had gross vascular invasion in radiography (70.6 vs $40.5 \%$ in $160 \mathrm{IU} \mathrm{m}^{-2}$ arm; $P=0.017, \chi^{2}$-test), as listed in Table 1 .

\section{Toxicity profiles and off-study causes}

A total of 205.5 cycles were administered (median, 2.25 cycles; range $0.5-6)$. At the end of the study, three $(8.8 \%)$ and five (13.5\%) subjects in the 320 and $160 \mathrm{IU} \mathrm{m}^{-2}$ arms, respectively, remained in the study and received the maximum of six cycles. The most common treatment-related adverse events were of grade 1-2 and associated with systemic and local allergic reaction and drug-related metabolic changes, that is, hypersensitivity/skin rash in $26.8 \%$, local tissue reaction at injection site in $22.5 \%$, hyperuricemia in $19.7 \%$, pruritus in $15.5 \%$, fatigue in $9.8 \%$, hyperammonemia in $4.2 \%$, fever in $7.0 \%$ and diarrhoea in $5.6 \%$, as listed in Table 2 . Thirteen patients $(18.3 \%)$ died during the study or within 1 month after their last treatment. These deaths were attributed to disease progression in 11, hepatic decompensation in 1 and oesophageal varices haemorrhage in another. The clinical characteristics of these 13 patients, at study entry, did not differ from those of the rest of 58 patients who remained alive for more than 1 month after last treatment.

\section{Pharmacodynamics and immunogenicity}

For both dosing cohorts, the circulating arginine level markedly decreased after the first dose (undetectable in majority of patients on day 8) and then rose gradually with extended time of treatment, which was accompanied by a reciprocal change in circulating citrulline levels, as shown in Figure 1A and B. The circulating arginine level remained at approximately $\leqslant 50 \%$ of the baseline level for about 10 weeks and 6 weeks in the 320 and $160 \mathrm{IU} \mathrm{m}^{-2}$ cohorts, respectively. Of note, the reported arginine levels were obtained 1 week after the administration of ADI-PEG 20 and thus may not accurately reflect the maximal and the duration of suppression of arginine levels attained during the week.

Antibodies directed against ADI-PEG 20 could be detected before cycle 2 (week 5 ) and generally reached a plateau before cycle 5 (week 17). The return to baseline levels of circulating arginine closely correlated with the increase in antibody titre (Figure 1C).
Table I Patient demographics

\begin{tabular}{|c|c|c|c|}
\hline Parameter/dose level & $320 \mathrm{IU} \mathrm{m}^{-2}$ & $1601 \mathrm{Im}^{-2}$ & Overall \\
\hline Case, number & 34 & 37 & 71 \\
\hline \multicolumn{4}{|l|}{ Gender } \\
\hline Male & $30(88.2 \%)$ & $29(78.4 \%)$ & $59(83.1 \%)$ \\
\hline Female & $4(11.8 \%)$ & $8(21.6 \%)$ & $12(16.9 \%)$ \\
\hline \multicolumn{4}{|l|}{ Age } \\
\hline Median & 55 & 56 & 55 \\
\hline Range & $31-82$ & $27-80$ & $27-82$ \\
\hline \multicolumn{4}{|l|}{ Karnofsky performance status } \\
\hline 100 & $5(14.7 \%)$ & $5(13.5 \%)$ & $10(14.1 \%)$ \\
\hline 90 & $21(61.2 \%)$ & $28(75.7 \%)$ & $49(69.0 \%)$ \\
\hline 80 & $8(23.5 \%)$ & $4(10.8 \%)$ & $12(16.9 \%)$ \\
\hline \multicolumn{4}{|l|}{ Child_Pugh class } \\
\hline A & $31(91.2 \%)$ & 34 (91.9\%) & $65(91.6 \%)$ \\
\hline B & $3(8.8 \%)$ & $3(8.1 \%)$ & $6(8.4 \%)$ \\
\hline \multicolumn{4}{|l|}{ HbsAg } \\
\hline Positive & $25(73.5 \%)$ & 24 (64.9\%) & $49(69.0 \%)$ \\
\hline Negative & $9(26.5 \%)$ & $13(35.1 \%)$ & $22(31.0 \%)$ \\
\hline \multicolumn{4}{|l|}{ Anti-HCV antibody } \\
\hline Positive & $8(23.5 \%)$ & II (29.7\%) & $19(26.8 \%)$ \\
\hline Negative & $24(76.5 \%)$ & $25(67.6 \%)$ & $51(71.8 \%)$ \\
\hline Unknown & $0(0.0 \%)$ & I (2.7\%) & I (1.4\%) \\
\hline \multicolumn{4}{|l|}{ Vascular invasion } \\
\hline Absent & $10(29.4 \%)$ & $22(59.5 \%)$ & $32(45.1 \%)$ \\
\hline Present & $24(70.6 \%)$ & $15(40.5 \%)$ & $39(54.9 \%)$ \\
\hline \multicolumn{4}{|l|}{ Extrahepatic metastases } \\
\hline Absent & $15(44.1 \%)$ & $15(40.5 \%)$ & $30(42.3 \%)$ \\
\hline Present & $19(55.9 \%)$ & $22(59.5 \%)$ & $41(57.7 \%)$ \\
\hline \multicolumn{4}{|l|}{ Prior therapy } \\
\hline Hepatic resection & II (32.4\%) & $18(48.6 \%)$ & $29(40.8 \%)$ \\
\hline $\begin{array}{l}\text { Transcatheter arterial } \\
\text { chemoembolization }\end{array}$ & $21(61.8 \%)$ & $25(67.6 \%)$ & $46(64.8 \%)$ \\
\hline Radiotherapy & $8(23.5 \%)$ & II (29.7\%) & $19(26.8 \%)$ \\
\hline Systemic therapy & $16(47.0 \%)$ & $15(40.5 \%)$ & $31(43.6 \%)$ \\
\hline Thalidomide alone & $4(11.8 \%)$ & $3(8.1 \%)$ & 7 (9.9\%) \\
\hline $\begin{array}{l}\text { Chemotherapy with/without } \\
\text { thalidomide }\end{array}$ & $8(23.5 \%)$ & $8(21.6 \%)$ & $16(22.5 \%)$ \\
\hline Anti-angiogenic therapy ${ }^{a}$ & $4(11.8 \%)$ & $4(10.8 \%)$ & $8(11.3 \%)$ \\
\hline
\end{tabular}

Abbreviation: $\mathrm{HbsAg}=$ hepatitis B surface antigen. ${ }^{a}$ Including Pl88 in 3, sorafenib in 2, sunitinib in I and bevacizumab in 2.

Table 2 Treatment-related adverse events

\begin{tabular}{|c|c|c|c|c|c|c|}
\hline \multirow[b]{2}{*}{ Adverse event } & \multicolumn{2}{|c|}{$\begin{array}{c}320 \mathrm{IU} \mathrm{m}^{-2} \\
(\mathrm{~N}=34)\end{array}$} & \multicolumn{2}{|c|}{$\begin{array}{c}160 \text { IU m }{ }^{-2} \\
(N=37)\end{array}$} & \multicolumn{2}{|c|}{$\begin{array}{l}\text { Overall } \\
(N=7 I)\end{array}$} \\
\hline & $\begin{array}{c}\text { Grade } \\
\text { I-2 }\end{array}$ & $\begin{array}{c}\text { Grade } \\
3-4\end{array}$ & $\begin{array}{c}\text { Grade } \\
I-2\end{array}$ & $\begin{array}{c}\text { Grade } \\
3-4\end{array}$ & $\begin{array}{c}\text { Grade } \\
\text { I-2 }\end{array}$ & $\begin{array}{c}\text { Grade } \\
3-4\end{array}$ \\
\hline Anaemia (\%) & 5.9 & & 2.7 & 2.7 & 4.2 & 1.4 \\
\hline Hypersensitivity/rash (\%) & 20.6 & & 32.4 & & 26.8 & \\
\hline Pruritus (\%) & 17.6 & & 13.5 & & 15.5 & \\
\hline Local reaction (\%) & 26.7 & & 18.9 & & 22.5 & \\
\hline Fatigue (\%) & 5.9 & 2.9 & 10.8 & & 8.4 & 1.4 \\
\hline Fever (\%) & 8.8 & & 5.4 & & 7.0 & \\
\hline Diarrhea (\%) & 8.8 & & 2.7 & & 5.6 & \\
\hline Hyperuricemia (\%) & 11.8 & 5.9 & 16.2 & 5.4 & $|4|$. & 5.6 \\
\hline Hyperammonemia (\%) & 5.9 & & 2.7 & & 4.2 & \\
\hline
\end{tabular}


A

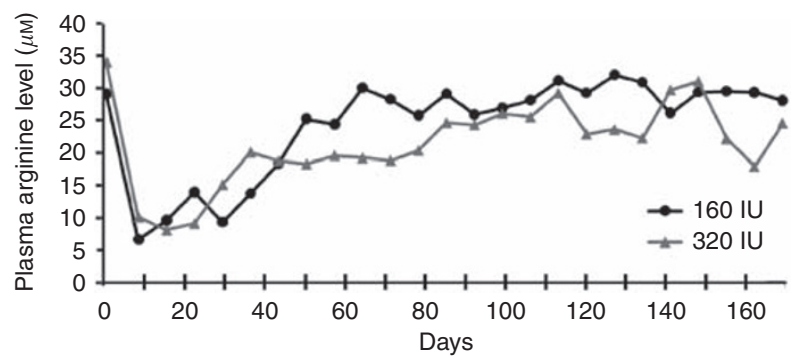

B
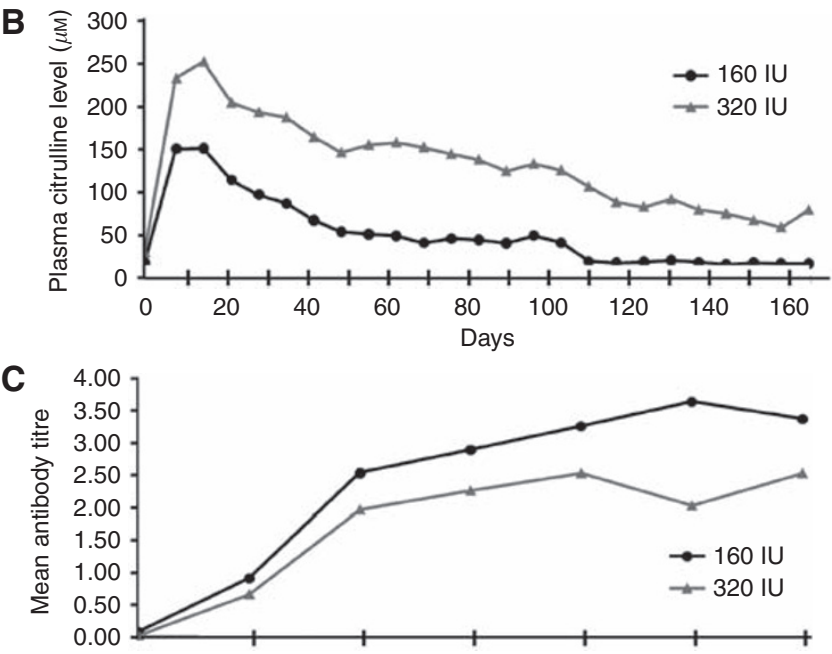

Baseline Cycle 1 Cycle 2 Cycle 3 Cycle 4 Cycle 5 Cycle 6

Figure I Changes of mean plasma (A) arginine and (B) citrulline levels, and (C) plasma titres of anti-ADI antibody after weekly administration of either 160 or $320 \mathrm{IU} \mathrm{m}^{-2}$ ADI-PEG 20 in patients with unresectable HCC.

\section{Response and survival}

There were no objective (complete or partial) tumour responders. The best tumour response was stable disease in 22 patients (31.0\%), progressive disease in $43(60.6 \%)$ and unevaluable in $6(8.4 \%)$. The DCR (complete/partial response + stable disease) for the ITT populations was $31.0 \%$ (22 of $71,95 \%$ confidence interval (CI): 20.5-43.1). Each dose cohort had 11 patients with stable disease as their best response. Among the 22 patients who showed stable disease at the end of cycle 2, six $(27.3 \%)$ remained progression free at the time of last assessment. As limited objective tumour response is commonly observed in most targeted agent trials, we also assessed the therapeutic efficacy of ADI-PEG 20 by monitoring changes of the serum AFP levels. To avoid the influence of non-tumour-originating AFP fluctuations (ie, those associated with hepatitis activity), we only assessed AFP response in patients with baseline AFP levels above $200 \mathrm{ng} \mathrm{ml}^{-1}$ (Liaw et al, 1986; Chen et al, 2009) and received treatments for at least 8 weeks. Of these 27 patients, the changes in AFP level after 8 weeks of ADI-PEG 20 treatment were $\geqslant 50 \%$ reduction in $3(11.1 \%),<50 \%$ reduction in $2(4.7 \%)$, less than onefold increase in $9(33.3 \%)$, one- to twofold increase in $7(25.9 \%)$ and more than twofold increase in $6(22.2 \%)$, as shown in Figure 2.

The median duration of disease control was 2.8 months for both dose cohorts, with the $95 \% \mathrm{CI}$ of $1.4-4.3$ months in $160 \mathrm{IU} \mathrm{m}^{-2}$ cohort and 2.4-3.3 months in $320 \mathrm{IU} \mathrm{m}^{-2}$ cohort. The median PFS and OS of the ITT population were 1.8 (95\% CI: $1.8-3.0)$ months and 7.3 (95\% CI: 4.7-9.9) months respectively. There was no statistical difference for both PFS and OS between the two study cohorts, with $P$-values 0.73 and 0.76 (log-rank test) respectively, as

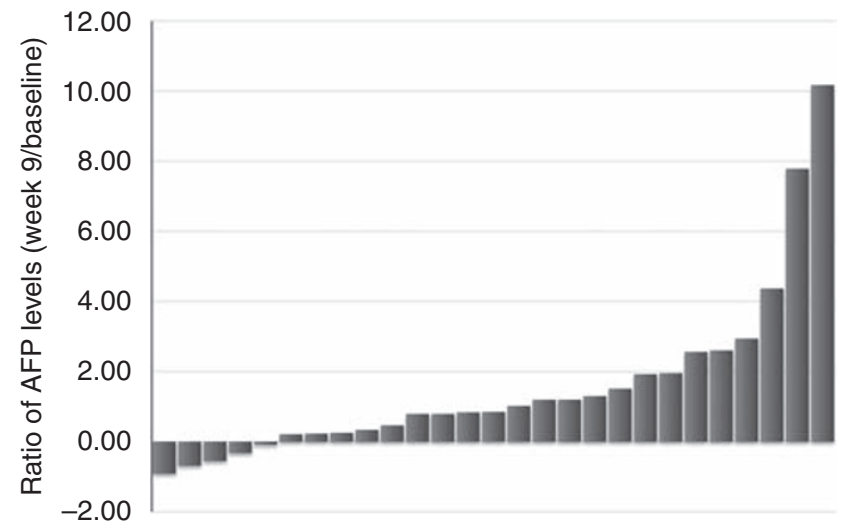

Figure 2 Waterfall plotting of $\alpha$-fetoprotein (AFP) level changes after 8 weeks of ADI-PEG 20 treatment in 27 patients whose baseline AFP above $200 \mathrm{ng} \mathrm{ml}^{-1}$.

Table 3 Therapeutic efficacy

\begin{tabular}{|c|c|c|c|}
\hline Items & $\begin{array}{c}320 \mathrm{IU} \mathrm{m}^{-2} \\
(\mathrm{~N}=34)\end{array}$ & $\begin{array}{c}160 \mathrm{IU} \mathrm{m}^{-2} \\
(\mathrm{~N}=37)\end{array}$ & $\begin{array}{l}\text { Overall } \\
(N=71)\end{array}$ \\
\hline \multicolumn{4}{|c|}{ Best tumor response, \% (95\% Cl) } \\
\hline $\begin{array}{l}\text { Objective response } \\
\text { Stable disease }\end{array}$ & 0 & 0 & 0 \\
\hline$\geqslant 8$ weeks & $32.4(16.6-48.1)$ & $29.7(\mid 5.0-44.4)$ & $31.0(20.2-41.8)$ \\
\hline$\geqslant 16$ weeks & $11.8(0.9-22.6)$ & $16.2(0.4-28.1)$ & $14.1(0.6-22.2)$ \\
\hline$\geqslant 24$ weeks & $5.9(0.0-13.8)$ & $10.8(0.1-20.8)$ & $8.4(0.2-14.9)$ \\
\hline $\begin{array}{l}\text { Median PFS (95\% Cl), } \\
\text { months }\end{array}$ & $1.9(1.8-3.5)$ & $1.8(1.8-3.5)$ & $1.8(1.8-3.0)$ \\
\hline $\begin{array}{l}\text { Median OS }(95 \% \mathrm{Cl}) \text {, } \\
\text { months }\end{array}$ & $6.2(2.8-9.6)$ & $8.4(3.6-13.1)$ & $7.3(4.7-9.9)$ \\
\hline
\end{tabular}

Abbreviations: $O S=$ overall survival; PFS $=$ progression-free survival. ${ }^{[2]}$ oth $O S$ and PFS were estimated by Kaplan-Meier analyses.

listed in Table 3. The survival curves of the two dose cohorts are plotted in Figure $3 \mathrm{~A}$ and $\mathrm{B}$.

The median survival of patients with baseline AFP level of $<10^{2}$ $(N=26), 10^{2}$ to $<10^{3}(N=12), 10^{3}$ to $<10^{4}(N=14)$ and $>10^{4}$ $(N=19) \mathrm{ng} \mathrm{ml}^{-1}$ was 11.8 (95\% CI: $\left.3.3-20.3\right)$ months, $15.7(95 \%$ CI: $7.6-23.8)$ months, 4.3 (95\% CI: $0-8.8)$ months and $4.1(95 \%$ CI: $3.0-5.2)$ months, respectively ( $P=0.0006$, log-rank test).

The proposed mechanism of action of ADI-PEG 20 treatment is the preferential starvation of tumour cells by arginine depletion, so the correlation between the duration of arginine depletion and OS was examined. Among the 61 subjects who had received at least one complete cycle (four doses) of treatment, the median survival of those with $(n=36)$ and without $(n=25)$ sustained depletion of plasma arginine level for 4 weeks was 10.0 (95\% CI: $2.1-17.9$ ) months and 5.8 (95\% CI: $1.4-10.1)$ months respectively $(P=0.251$, log-rank test; Figure 4). Of the 36 patients showing depletion of plasma arginine for 4 weeks, 13 patients continued to show depletion of plasma arginine for 8 or more weeks. The median OS of these 13 patients was 15.2 months (95\% CI: $1.2-29.1$ ).

In addition, we also explored the correlation between the expression of ASS in tumour tissue and OS. Formalin-fixed, paraffin-embedded archival tumour specimens from 44 patients were subjected to immunohistochemical study using anti-ASS monoclonal antibody (Polaris Pharmaceuticals Inc.) and visualised by a biotinylated horse anti-mouse, streptavidin-HRP system (Vector Labs Inc., Burlingame, CA, USA). Of them, 33 (75\%) were ASS deficient and $11(25 \%)$ were ASS positive. The median OS of all 44 patients was 5.9 (95\% CI: 0.6-11.2) months, whereas the median OS of patients with ASS-deficient and ASS-positive 


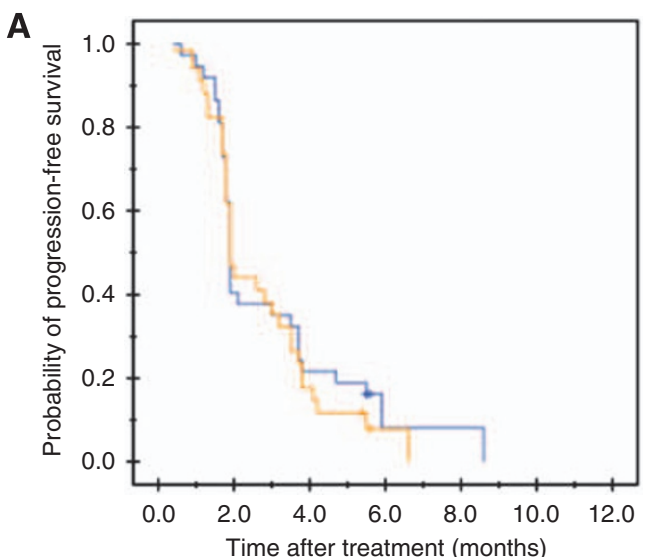

No. of patients at risk

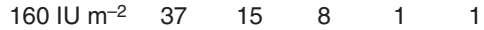

$320 \mathrm{IU} \mathrm{m}^{-2} \quad 34 \quad 16 \quad 6 \quad 1 \quad 0$

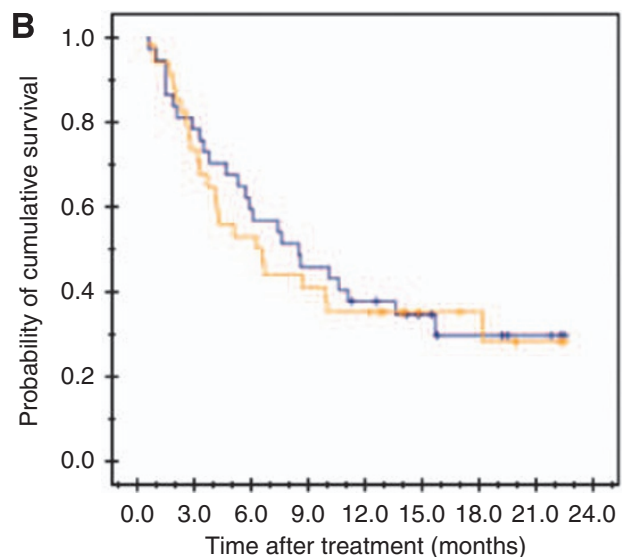

No. of patients at risk

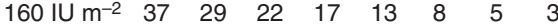

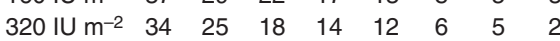

Figure 3 Progression-free $(\mathbf{A})$ and overall survival $(\mathbf{B})$ curves according to the ADI-PEG 20 dose administered, $160 \mathrm{IU} \mathrm{m} \mathrm{m}^{-2}$ (blue line) and $320 \mathrm{IU} \mathrm{m}^{-2}$ (orange line), with $P$-values of 0.73 and 0.76 (log-rank test), respectively.

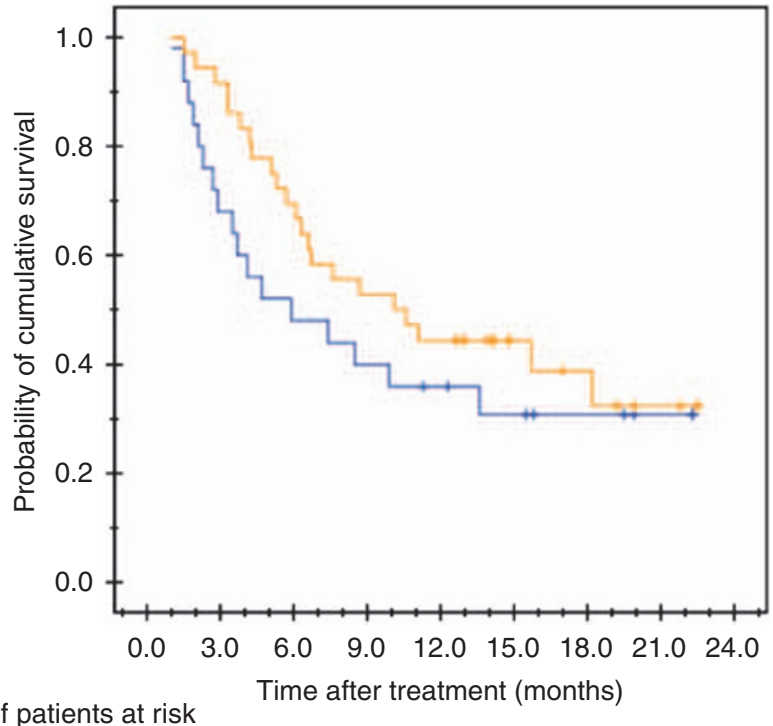

No. of patients at risk

$\begin{array}{lllllllll}<4 \text { weeks } & 25 & 17 & 12 & 10 & 8 & 6 & 4 & 2 \\ \geqslant 4 \text { weeks } & 36 & 33 & 25 & 19 & 16 & 8 & 6 & 3\end{array}$

Figure 4 Overall survival curves in patients with depletion of circulating arginine for $\geqslant 4$ weeks (orange line) and $<4$ weeks (blue line) of duration after ADI-PEG 20 treatment $(P=0.25$ I, log-rank test).

tumours was $8.3(95 \%$ CI: $3.4-14.0)$ and 3.3 (95\% CI: $1.3-2.5)$ months $(P=0.065$, log-rank test $)$.

\section{DISCUSSION}

In this study, we have shown that weekly intramuscular injection of ADI-PEG 20 at doses of 160 or $320 \mathrm{IU} \mathrm{m}^{-2}$ could achieve a DCR of $31.0 \%$ (95\% CI: $20.5-43.1$ ) and an OS of 7.3 (95\% CI: $4.7-9.9$ ) months in a previously heavily treated Asian advanced HCC population. The majority of the patients enrolled in this study $(88.7 \%)$ had failed one or more previous treatment modalities for HCC, including systemic therapy in $43.6 \%$ patients. As compared with the initial reports in smaller Caucasian cohorts, minimal objective tumour response was observed in the studies of Glazer et al (2010) and ours (Curley et al, 2003; Izzo et al, 2004). However, the DCRs in current study and the Caucasian phase II study were 31 and 63\% respectively (Glazer et al, 2010). The causes for discrepancy remain unknown, but may be attributed to the higher percentage of patients with previous systemic treatment in our study (43.6 vs 1.3\%) and/or a potential difference in how HBV- and HCV-related HCC respond to the arginine deprivation therapy. Unfortunately, Glazer et al reported their survival data as mean survival after the diagnosis of unresectable HCC, which makes the comparison of survival after treatment between the two studies impossible.

However, the DCR and OS observed in our study were comparable with that of $35 \%$ and 6.5 (95\% CI: 5.6-7.6) months for patients who received sorafenib in a phase III study in Asia-Pacific region (Cheng et al, 2009). In comparison, $43.6 \%$ of our patients had failed previous systemic therapy including chemotherapy and anti-angiogenic therapy, which was not allowed in the Asia-Pacific sorafenib trials. In addition, ADI-PEG 20 was relatively well tolerated as compared with sorafenib. The major toxicities of ADI-PEG 20 were of grades 1-2 local and/or allergic reactions, which were distinct from those adverse events observed in association with cytotoxic or molecular targeted agents. However, the impact of ADI-PEG 20 on the natural course of advanced HCC has to be validated further by randomised phase III trials. Furthermore, the effectiveness and non-overlapping toxicity of ADI-PEG 20 make it a potential candidate to be combined with other promising agent(s) for future clinical trials in advanced HCC.

Our pharmacodynamic analysis confirmed that weekly treatment with $160 \mathrm{IU} \mathrm{m}^{-2}$ was sufficient to deplete circulating arginine for 7 days (Izzo et al, 2004). The $320 \mathrm{IU} \mathrm{m}^{-2}$ dose in this study was chosen to investigate if a further increase in dosage would result in an even more prolonged depletion of arginine and thus possibly greater efficacy. Anti-ADI-PEG 20 antibody was detectable after week 4 in some patients, and its frequency and titre increased after repetitive administration of ADI-PEG 20, which was accompanied by a gradual return of the circulating arginine levels in both study arms. The median period of sustained reduction of circulating arginine to $<50 \%$ of baseline levels in the 160 and $320 \mathrm{IU} \mathrm{m}^{-2}$ dose groups was approximately 6 weeks and 10 weeks respectively. However, the DCR and OS were similar in both dose cohorts. It should be noted that the circulating arginine levels reported in this study were obtained 7 days after administration of the study drug. The extent to which arginine was depleted immediately after 
administration of the study drug and the duration of this level of depletion is not known. It warrants further investigation. However, based on the results of this study, weekly $160 \mathrm{IU} \mathrm{m}^{-2}$ should remain as the recommended dosing schedule in future trials.

A post hoc analysis of the survival data revealed a potential correlation between duration of arginine deprivation and survival in this limited patient population. Patients with depletion of circulating arginine for $\geqslant 4$ weeks had a trend towards better survival than those with depletion of arginine for $<4$ weeks. This finding is consistent with what has been conceived for antiangiogenic therapy, an alternative selective starvation therapy (Slaton et al, 1999). The return of circulating arginine levels was preceded by the rising titre of anti-ADI-PEG 20 antibody. Therefore, the therapeutic efficacy of ADI-PEG 20 therapy may be further improved by modifying the antigenic epitope of ADI and/or by combining ADI-PEG 20 with immune modulation or cytotoxic therapy to diminish the production of anti-ADI-PEG 20 antibody. Furthermore, there was also a trend towards better survival in patients with ASS-deficient HCC relative to those who were ASS positive. The potential of using ASS status as a predictive biomarker and/or selection criteria for arginine deprivation therapy should be further investigated in a larger patient population study.

Recent reports have reported that lowering peripheral blood arginine can result in anti-angiogenesis by inhibition of nitric oxide synthesis, alteration of immune cell tumour surveillance and induction of autophagy (Gong et al, 2003; Bronte and Zanovello, 2005; Shen et al, 2006; Peranzoni et al, 2007; Bowles et al, 2008; Kim et al, 2009; Delage et al, 2010). These can all be considered as additional mechanisms of action of ADI-PEG 20.
In conclusion, ADI-PEG 20 is safe and efficacious in stabilising the progression of advanced HCC in an Asian population. On the basis of the results of this study, a multi-national phase III study for HCC is being planned. In addition, the exceptional safety profile and the unique mechanisms of action suggest that ADI-PEG 20 is a good candidate to be used in combination with other molecular targeting or cytotoxic agents. The planning for combination studies in patients with other ASS-deficient tumours is currently underway.

\section{ACKNOWLEDGEMENTS}

We thank the centres and physicians participating in the study: National Taiwan University Hospital (Po-Chin Liang); Veterans General Hospital, Taipei (Teh-la Huo, Wei-Ping Lee, Chung-Pin Li); Chang-Gung Memorial Hospital, Linkou (Jen-Shi Chen); Mackay Memorial Hospital, Taipei (Ruey-Kuen Hsieh); Chung-Ho Memorial Hospital, Kaohsiung Medical University, Kaohsiung (Ming-Lung Yu); Taipei City Hospital, Renai Branch (Chih-Lin Lin); Chang-Gung Memorial Hospital, Kaohsiung (Jing-Houng Wang, Kwong-Ming Kee). This study was sponsored by Polaris Pharmaceuticals Inc. San Diego, CA, USA

\section{Conflict of interest}

Consultant or Advisory Role: Pei-Jer Chen and Li-Tzong Chen, Polaris Pharmaceuticals.

Honoraria: Li-Tzong Chen, Pei-Jer Chen, Polaris Pharmaceuticals. Research Funding: Pei-Jer Chen, TDW Pharmaceuticals.

Employment or Leadership Position, and stock ownership: James Thomson, Polaris Pharmaceuticals.

\section{REFERENCES}

Abou-Alfa GK, Venook AP (2008) The impact of new data in the treatment of advanced hepatocellular carcinoma. Curr Oncol Rep 10: 199-205

Bowles TW, Kim R, Galante J, Parsons CM, Virudachalam S, Kung HJ, Bold RJ (2008) Pancreatic cancer cell lines deficient in argininosuccinate synthetase are sensitive to arginine deprivation by arginine deiminase. Int J Cancer 123: 1950 - 1955

Bronte V, Zanovello P (2005) Regulation of immune responses by L-arginine metabolism. Nat Rev Immunol 5: 641-654

Chen CH, Su WW, Yang SS, Chang TT, Cheng KS, Lin HH, Wu SS, Lee CM, Changchien CS, Chen CJ, Sheu JC, Chen DS, Lu SN (2006) Long-term trends and geographic variations in the survival of patients with hepatocellular carcinoma: analysis of 11312 patients in Taiwan. J Gastroenterol Hepatol 21: $1561-1566$

Chen LT, Shiah HS, Chao Y, Chang JY, Cheng LT, Whang-Peng J (2009) Alpha-fetoprotein response in advanced hepatocellular carcinoma receiving cytostatic agent. J Clin Oncol 27: e271

Cheng AL, Kang YK, Chen Z, Tsao CJ, Qin S, Kim JS, Luo R, Feng J, Ye S, Yang TS, Xu J, Sun Y, Liang H, Liu J, Wang J, Tak WY, Pan H, Burock K, Zou J, Voliotis D, Guan Z (2009) Efficacy and safety of sorafenib in patients in the Asia-Pacific region with advanced hepatocellular carcinoma: a phase III randomized, double-blind, placebo-controlled trial. Lancet Oncol 10: $25-34$

Curley SA, Bomalaski JS, Ensor CM, Holtsberg FW, Clark MA (2003) Regression of hepatocellular carcinoma in a patient treated with arginine deiminase. Hepatogastroenterology 50: 1208-1211

Delage B, Fennell DA, Nicholson L, McNeish I, Lemoine NR, Crook T, Szlosarek PW (2010) Arginine deprivation and arginino-succinate synthetase expression in the treatment of cancer. Int $J$ Cancer 126: $2762-2772$

Dillon BJ, Prieto VG, Curley SA, Enso CM, Holtsberg FW, Bomalaski JS, Clark MA (2004) Incidence and distribution of argininosuccinate synthetase deficiency in human cancers: a method for identifying cancers sensitive to arginine deprivation. Cancer 100: 826-833
Di Maio M, De Maio E, Perrone F, Pignata S, Daniele B (2002) Hepatocellular carcinoma: systemic treatments. J Clin Gastroenterol 35(5 Suppl 2): S109-S114

El-Serag HB, Rudolph KL (2007) Hepatocellular carcinoma: epidemiology and molecular carcinogenesis. Gastroenterology 132: 2557-2576

Ensor CM, Holtsberg FW, Bomalaski JS, Clark MA (2002) Pegylated arginine deiminase (ADI-SS PEG $_{20,000 \mathrm{mw}}$ ) inhibits human melanomas and hepatocellular carcinomas in vitro and in vivo. Cancer Res 62: $5443-5450$

Glazer ES, Piccirillo M, Albino V, Di Giacomo R, Palaia R, Mastro AA, Beneduce G, Castello G, De Rosa V, Petrillo A, Ascierto PA, Curley SA, Izzo F (2010) Phase II study of pegylated arginine deiminase for nonresectable and metastatic hepatocellular carcinoma. J Clin Oncol 28: $2220-2226$

Gong H, Pöttgen C, Stüben G, Havers W, Stuschke M, Schweigerer L (2003) Arginine deiminase and other antiangiogenic agents inhibit unfavorable neuroblastoma growth: potentiation by irradiation. Int $J$ Cancer 106: $723-728$

Holtsberg FW, Ensor CM, Steiner MR, Bomalaski JS, Clark MA (2002) Poly(ethylene glycol) (PEG) conjugated arginine deiminase: effects of PEG formulations on its pharmacological properties. J Control Release 80: $259-271$

Izzo F, Marra P, Beneduce G, Castello G, Vallone P, De Rosa V, Cremona F, Ensor CM, Holtsberg FW, Bomalaski JS, Clark MA, Ng C, Curley SA (2004) Pegylated arginine deiminase treatment of patients with unresectable hepatocellular carcinoma: results from phase I/II studies. J Clin Oncol 22: $1815-1822$

Kaplan EL, Meier P (1958) Nonparametric estimation from incomplete observation. J Am Stat Assoc 53: $457-481$

Kenny GE, Pollock ME (1963) Mammalian cell cultures contaminated with pleuropneumonia-like organisms. I. Effect of pleuropneumonialike organisms on growth of established cell strains. J Infect Dis 112: $7-16$ 
Kim RH, Bowles TL, Kung HJ (2009) ADI, autophagy and apoptosis: metabolic stress as a therapeutic option for prostate cancer. Autophagy 5: $567-568$

Kraemer PM (1964) Mycoplasma (PPLO) from covertly contaminated tissue cultures: differences in arginine degradation between strains. Proc Soc Exp Biol Med 117: 910-918

Kraemer PM, Defendi V, Hayflick L, Manson LA (1963) Mycoplasma (PPLO) strains with lytic activity for murine lymphoma cells in vitro. Proc Soc Exp Biol Med 112: $381-387$

Liaw YF, Tai DI, Chen TJ, Chu CM, Huang MJ (1986) Alpha-fetoprotein changes in the course of chronic hepatitis: relation to bridging hepatic necrosis and hepatocellular carcinoma. Liver 6: 133-137

Llovet J, Ricci S, Mazzaferro V, Hilgard P, Gane E, Blanc JF, de Oliveira AC, Santoro A, Raoul JL, Forner A, Schwartz M, Porta C, Zeuzem S, Bolondi L, Greten TF, Galle PR, Seitz JF, Borbath I, Häussinger D, Giannaris T, Shan M, Moscovici M, Voliotis D, Bruix J, SHARP Investigators Study Group (2008) Sorafenib in advanced hepatocellular carcinoma. $N$ Engl Med 359: 378 - 390

Llovet JM (2005) Updated treatment approach to hepatocellular carcinoma. J Gastroenterol 40: $225-235$

O'Neill BH, Venook AP (2007) Hepatocellular carcinoma: the role of the North American GI Steering Committee Hepatobiliary Task Force and the advent of effective drug therapy. Oncologist 12: 1425-1432

Peranzoni E, Marigo I, Dolcetti L, Ugel S, Sonda N, Taschin E, Mantelli B, Bronte V, Zanovello P (2007) Role of arginine metabolism in immunity and immunopathology. Immunobiology 212: 795-812

Rogers QR (1994) Species Variation in Arginine Requirements, In Proceedings from a Symposium Honoring Willard J Visek-from Ammonia to Cancer and Gene Expression pp 9-21. Agriculture Experiment Station, University of Illinois: Urbana, IL

Ryder SD (2003) Guidelines for the diagnosis and treatment of hepatocellular carcinoma (HCC) in adults. Gut 52(Suppl 3): iiil - iii8
Shen LJ, Beloussow K, Shen WC (2006) Modulation of arginine metabolic pathways as the potential anti-tumor mechanism of recombinant arginine deiminase. Cancer Lett 231: $30-35$

Simon RM (1989) Optimal two-stage designs for phase II clinical trials. Control Clin Trials 10: $1-10$

Slaton JW, Perrotte P, Inoue K, Dinney CP, Fidler IJ (1999) Interferon $\backslash$ alphal\} mediated down-regulation of angio. Clin Cancer Res 5: 2726-2734

Sugimura K, Ohno T, Fukuda S, Wada Y, Kimura T, Azuma I (1990) Tumor growth inhibitory activity of a lymphocyte blastogenesis inhibitory factor. Cancer Res 50: 345 - 349

Sun CA, Wu DM, Lin CC, Lu SN, You SL, Wang LY, Wu MH, Chen CJ (2003) Incidence and cofactors of hepatitis $C$ virus-related hepatocellular carcinoma: a prospective study of 12,008 men in Taiwan. Am J Epidemiol 157: $674-682$

Takaku H, Misawa S, Hayashi H, Miyazaki K (1993) Chemical modification by polyethylene glycol of the anti-tumor enzyme arginine deiminase from Mycoplasma arginini. Jpn J Cancer Res 84: 1195-1200

Takaku H, Takase M, Abe S-I, Hayashi H, Miyazaki K (1992) In vivo antitumor activity of arginine deiminase purified from Mycoplasma arginini. Int J Cancer 51: 244-249

Tapiero H, Mathe G, Couvreur P, Tew KD (2002) I. Arginine. Biomed Pharmacother 56: $439-445$

Therasse P, Arbuck SG, Eisenhauer EA, Wanders J, Kaplan RS, Rubinstein L, Verweij J, Van Glabbeke M, van Oosterom AT, Christian MC, Gwyther SG (2002) New guidelines to evaluate the response to treatment in solid tumors. J Natl Cancer Inst 92: 205-216

Tytell AA, Neuman RE (1960) Growth response of stable and primary cell cultures to L-ornithine, L-citrulline, and L-arginine. Exp Cell Res 20: 84-91

Yu AS, Keeffe EB (2003) Management of hepatocellular carcinoma. Rev Gastroenterol Disord 3: 8-24

Zhu AX (2008) Development of sorafenib and other molecularly targeted agents in hepatocellular carcinoma. Cancer 112: 250-259 